\title{
Benefits Of Using Fiber on Impact Resistance of FRC Slabs
}

\author{
Jin-Young Lee ${ }^{1}$, Tian-Feng Yuan ${ }^{1}$, Doo-Yeol Yoo ${ }^{2}$, and Young-Soo Yoon ${ }^{*}$ \\ ${ }^{1}$ School of Civil, Environmental and Architectural Engineering, Korea University, Seoul, Korea \\ ${ }^{2}$ Department of Architectural Engineering, Hanyang University, Seoul, Korea
}

\begin{abstract}
The recent increase in terrorist attacks and natural disasters has led to increased requirements for concrete structures to be impact resistant. Concrete normally has excellent impact resistance to such extreme loads in comparison with other construction materials. Nevertheless, existing concrete structures designed without consideration of the impact or blast load with high strain rate are endangered by those unexpected extreme loads. Therefore, the impact resistances of two-way concrete slabs were studied by conducting the multiple impact test. Various fiber reinforcements (Hooked-steel fiber, straight-steel fiber) were considered as variables. In the impact test, the impact load was applied to each specimen by dropping weight on the specimen from a certain height. The applied impact load level was adjusted by changing the height of the weight. Specimens were used for impact loading test, each measuring $1,600 \mathrm{~mm}$ long, $1,600 \mathrm{~mm}$ wide, and $105 \mathrm{~mm}$ thick. All slabs were doubly reinforced (top and bottom layer) and each layer in a specimen had the same reinforcement layout. The performances of the specimens under the impact load were evaluated by comparing their reaction force, deflection, and surface damage. The impact test was stopped when the measured reaction force started to decrease. Based on the impact test, it was observed that the resistance against impact load can be improved by using fiber reinforced concrete.
\end{abstract}

\section{Introduction}

The recent increase in terrorist attacks and natural disasters has led to increased requirements for concrete structures to be impact resistant. Concrete normally has excellent impact resistance to such extreme loads in comparison with other construction materials. Nevertheless, existing concrete structures designed without consideration of the impact or blast load with high strain rate are endangered by those unexpected extreme loads. Therefore, the impact resistances of two-way concrete slabs were studied by conducting the multiple impact test. The objective of this study is to evaluate impact damage of structural members and to compare the impact resistance according to the material properties. Before the structural tests, compressive strength and tensile strength were measured through basic material tests. In this study, dynamic impact resistance was evaluated by drop-weight

\footnotetext{
*Corresponding author: ysyoon@korea.ac.kr
} 
impact tests on two-way RC slabs, and the impact resistance was compared by steel fiber contents and concrete strength. In this purpose, two-way RC slabs were tested under dropweight impact loading condition [1-6].

\section{Experimental program}

In this experimental study, impact tests were carried out on RC slabs with various strength from $25 \mathrm{MPa}$ to $180 \mathrm{MPa}$. The types of fibers were also considered as test variables. Therefore, there are four variables used in this study.

-NC - Normal Concrete

-SFRC - Steel Fiber Reinforce Concrete

-UHPC - Ultar High Performance Concrete

-HPFRCC. - High Performance Fiber Reinforced Cementitious Composites

\subsection{Material properties and mix design}

\subsubsection{Steel fiber}

In Fig. 1 two types of steel fiber were shown. The straight steel fiber was used in HPFRCC, and the hook type steel fiber was used in SFRC in this study. The material properties of fibers were shown in Table 1.

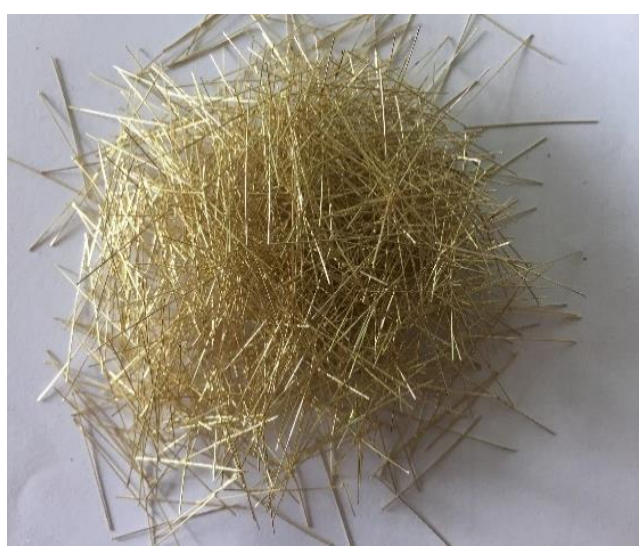

Straight type

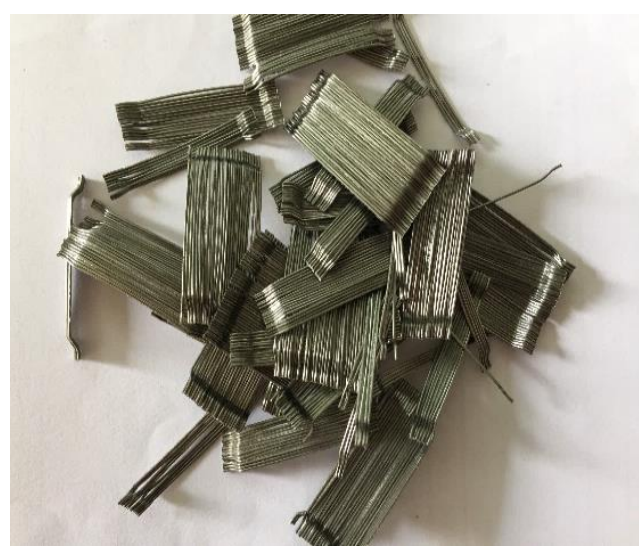

Hooked-end type

Fig. 1 Steel Fiber

Table 1. Material properties of steel fiber reinforcement

\begin{tabular}{|c|c|c|c|}
\hline Type & Length $(\mathbf{m m})$ & Diameter $\mathbf{( m m )}$ & Aspect ratio \\
\hline Straight & 19.5 & 0.2 & 95 \\
\hline Hook & 35 & 0.55 & 65 \\
\hline
\end{tabular}




\subsubsection{Mix design}

The main variables in this mix design table are $w / b$ and steel fiber content and type. The details of mixture were shown in Table 2.

Table 2. Mix. proportion

\begin{tabular}{|c|c|c|c|c|c|c|c|c|}
\hline \multirow{2}{*}{$\begin{array}{l}\text { Nomen- } \\
\text { clature }\end{array}$} & \multirow{2}{*}{$\begin{array}{l}\text { W/B } \\
(\%)\end{array}$} & \multirow{2}{*}{$\begin{array}{c}\text { Steel } \\
\text { Fiber } \\
\left(\mathrm{kg} / \mathbf{m}^{3}\right)\end{array}$} & \multirow{2}{*}{$\begin{array}{c}\text { Steel } \\
\text { Fiber } \\
\text { (\%) }\end{array}$} & \multicolumn{5}{|c|}{ Unit Weighty $\left(\mathrm{kg} / \mathrm{m}^{3}\right)$} \\
\hline & & & & $\mathbf{W}$ & $\mathbf{C}$ & $\mathbf{G}$ & $\mathbf{S}$ & SF \\
\hline $\begin{array}{c}\text { HPFRCC } \\
180-F 2.0\end{array}$ & 13.4 & 156.0 & 2.0 & 231.0 & 734.9 & 0.0 & 808.4 & 73.5 \\
\hline $\begin{array}{c}\text { UHPC } \\
180-F 0.0\end{array}$ & 13.4 & 0.0 & 0.0 & 231.0 & 734.9 & 0.0 & 808.4 & 73.5 \\
\hline $\begin{array}{c}\text { SFRC } \\
60 \mathrm{MPa}- \\
\text { F2.0 }\end{array}$ & 35.9 & 156.0 & 2.0 & 163.0 & 454.0 & 992.0 & 707.0 & 0.0 \\
\hline $\begin{array}{c}\mathrm{NC} \\
60 \mathrm{MPa}- \\
\text { F0.0 }\end{array}$ & 35.9 & 0.0 & 0.0 & 163.0 & 454.0 & 992.0 & 707.0 & 0.0 \\
\hline
\end{tabular}

\subsection{Test specimens}

As shown in Fig. 2, two-way slabs of $1600 \times 1600 \times 105 \mathrm{~mm}$ were tested in this study. there were four variables for this experimental program. Various types of concrete mix were used in this study shown in Table 2. As shown in Fig. 2, SD400-D10 reinforcing bars were used with spacing of $240 \mathrm{~mm}$.
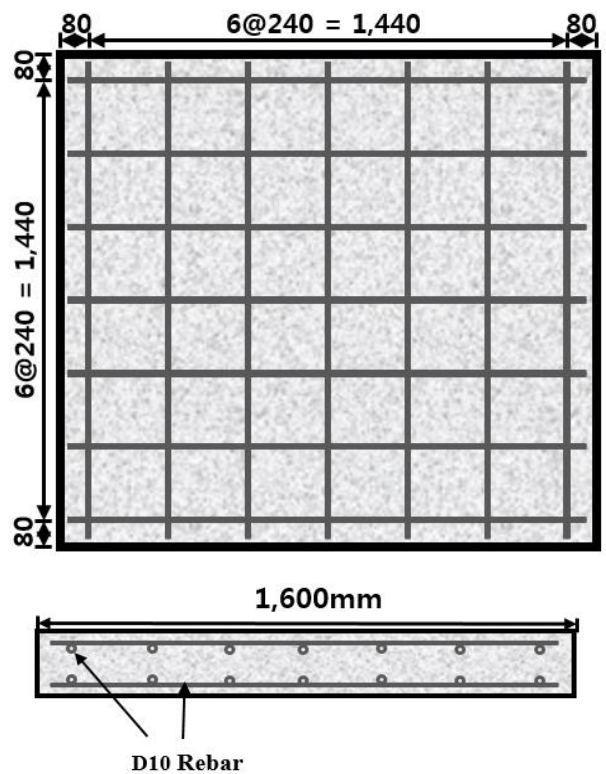

Fig. 2 Details of specimens 


\section{Test results and discussion}

\subsection{Effect of fiber in FRC slabs}

\subsubsection{Maximum Reaction and Impact Force at Each Loading Step}

In the Drop-weight impact tests, the impact and reaction forces are expressed in Table 3. The number of blows of the test varies depending on the type and mixing ratio of the cement composite. In case of UHPC-180-F0.0, the specimen was failed in $2^{\text {nd }}$ blow in spite of high compressive strength. HPFRCC and SFRC which were strengthened with steel fiber, can resist the $11^{\text {th }}$ and $6^{\text {th }}$ blow, respectively. Therefore, using fiber in structural member subjected to impact load has a lot of benefits in impact resistance.

Table 3. Impact and reaction force

\begin{tabular}{|c|c|c|c|c|}
\hline Specimens & $\begin{array}{c}\text { Blow } \\
\text { No. }\end{array}$ & $\begin{array}{c}\text { H } \\
(\mathbf{m m})\end{array}$ & $\begin{array}{c}\text { Impact force } \\
(\mathbf{k N})\end{array}$ & $\begin{array}{c}\text { Reaction force } \\
(\mathbf{k N})\end{array}$ \\
\hline \multirow{3}{*}{ HPFRCC-180-F2.0 } & 1. & 500 & 446.36 & 119.14 \\
\cline { 2 - 5 } & 7. & 2000 & 569.96 & 369.84 \\
\cline { 2 - 5 } & 11. & 2000 & - & 246.23 \\
\hline \multirow{3}{*}{ UHPC-180-F0.0 } & 1. & 500 & 303.62 & 145.38 \\
\cline { 2 - 5 } & 2. & 750 & 172.74 & 136.26 \\
\hline \multirow{3}{*}{ SFRC-60-F2.0 } & 1. & 500 & 349.24 & 195.71 \\
\cline { 2 - 5 } & 3. & 1250 & 351.10 & 217.59 \\
\cline { 2 - 5 } & 6. & 1750 & 259.08 & 254.28 \\
\hline \multirow{2}{*}{ NC-60-F0.0 } & 1. & 500 & 303.62 & 145.38 \\
\cline { 2 - 5 } & 2. & 750 & 172.74 & 136.26 \\
\hline
\end{tabular}

As shown in the Fig. 3, the shape of cracks and punching shear can be shown in the final fracture patterns. Both NC and UHPC showed punching shear. However, the SFRC, HPFRCC slabs reinforced with steel fiber didn't show punching shear.

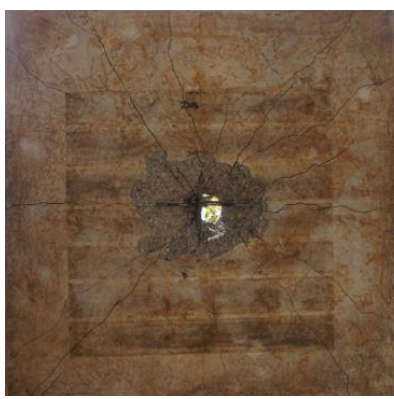

NC-60-F0.0

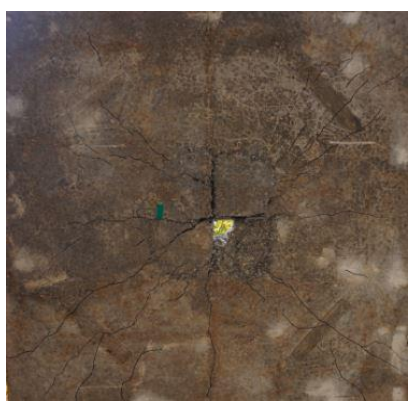

SFRC-60-F2.0 


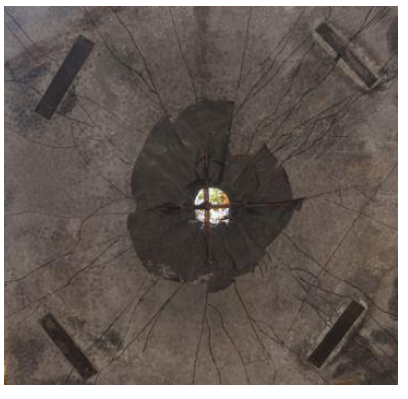

UHPC-180-F0.0

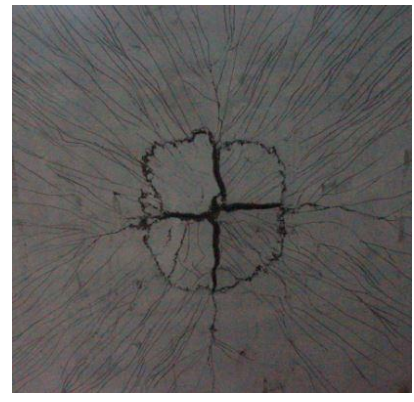

HPFRCC-180-F2.0

Fig. 3 Final fracture pattern of slab

\subsubsection{Maximum Crack Width at Each Loading Step}

Table. 4. shows the crack width at each loading steps of impact test. In case of NC-60-F0.0 and UHPC-180-F0.0, the crack width could not be measured because the critical shear crack occurred after $1^{\text {st }}$ blow. SFRC-60-F2.0 and UHPFRCC-180-F2.0 failed in $6^{\text {th }}$ and $11^{\text {th }}$ blow. For the comparison, the crack width of SFRC-60-F2.0 and UHPFRCC-180-F2.0 in $5^{\text {th }}$ blow are $5 \mathrm{~mm}$ and $3 \mathrm{~mm}$. In this results, it was confirmed that the strength of matrix can increase the crack resistance and the fiber is the very useful method for resisting crack propagation.

Table 4. Crack Width at Each Loading Step

\begin{tabular}{|c|c|c|c|c|}
\hline \multirow{2}{*}{ Loading Step } & \multicolumn{4}{|c|}{ Maximum Crack Width } \\
\cline { 2 - 5 } & NC-60-F0.0 & $\begin{array}{c}\text { SFRC-60 } \\
- \text {-F2.0 }\end{array}$ & $\begin{array}{c}\text { UHPC- 180 } \\
\text {-F0.0 }\end{array}$ & $\begin{array}{c}\text { UHPFRCC-18 } \\
\mathbf{0 - F 2 . 0}\end{array}$ \\
\hline Step \#1. (500mm) & 0.6 & 0.5 & 0.5 & 0.2 \\
\hline Step \#2. (750mm) & Punching & 0.7 & Punching & 0.35 \\
\hline Step \#3. (1000mm) & - & 0.9 & - & 0.8 \\
\hline Step \#4. (1250mm) & - & 1.4 & - & 2.0 \\
\hline Step \#5. (1500mm) & - & 5.0 & - & 3.0 \\
\hline Step \#6. (1750mm) & - & End & - & 4.5 \\
\hline Step \#7. (2000mm) & - & - & - & 6.5 \\
\hline Step \#8. (2000mm) & - & - & - & 7.5 \\
\hline Step \#9. (2000mm) & - & - & - & 8 \\
\hline Step \#10. (2000mm) & - & - & - & 19 \\
\hline Step \#11. (2000mm) & - & - & - & End \\
\hline
\end{tabular}

\subsubsection{Maximum Deflection and Residual Deflection at Each Loading Step}

Fig. 4 is the graph shows maximum deflection and residual deflection of the specimens. It can be confirmed that the resistance against the impact loading in terms of residual and maximum deflection can be increased by the steel fiber reinforcement. In the both case of $\mathrm{NC}$ and UHPC, deflections were decreased significantly. 


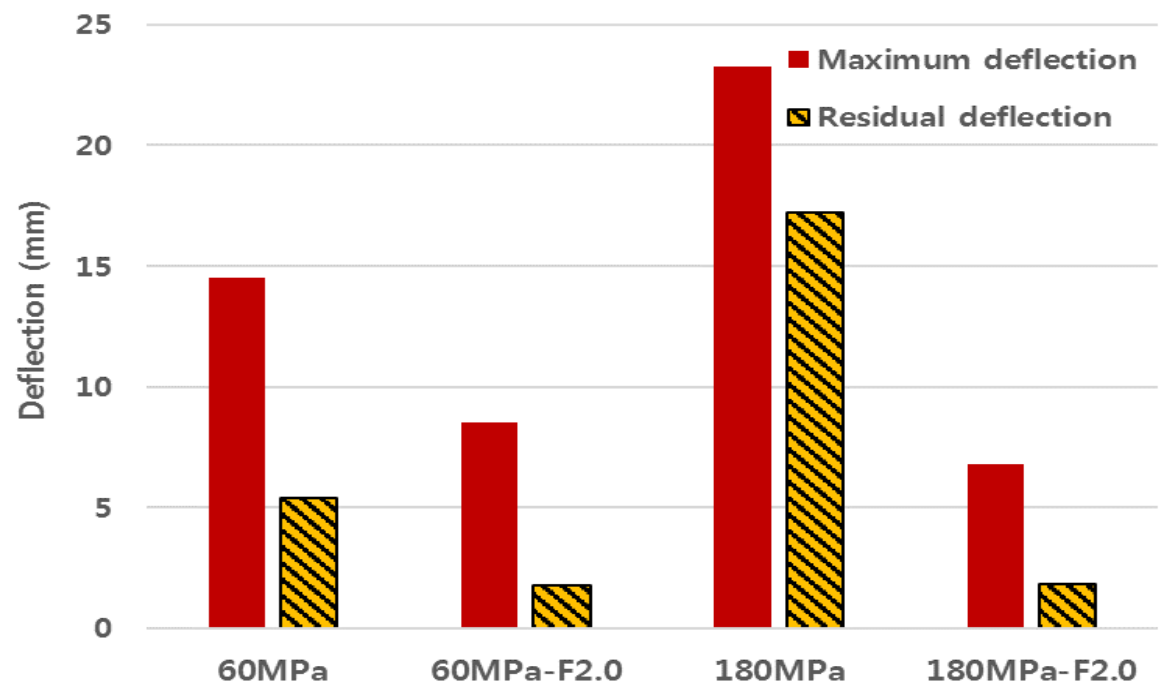

Fig. 4 Maximum Deflection and Residual Deflection (Step \#1.)

\subsubsection{Total Imparted Energy until Failure}

Assuming the kinetic energy can be transferred to the impact energy without any loss, total imparted energy until failure of each specimen can be obtained. Although it varies depending on the loading history, total imparted energy can be a useful index to make a relative comparison between those specimens tested in this program. As shown in Table 5., the same dissipated energy was measured in NC-60-F0.0 and HPFRCC-180-F0.0, which are not contain the steel fiber. On the other hand, the SFRC slab with steel fiber showed $26 \%$ increased dissipated energy compared with NC-60-F0.0. And HPFRCC-180-F2.0 showed increase of $73.55 \%$ in dissipated energy compared with UHPC-180-F0.0. In this results, it can be confirmed that the reinforcing effect of steel fiber is greater in HPFRCC than in SFRC.

Table 5. Total imparted energy until failure

\begin{tabular}{|c|c|c|c|}
\hline Specimens & $\begin{array}{c}\text { Loading step } \\
\text { at failure }\end{array}$ & $\begin{array}{c}\text { Total imparted energy until fa } \\
\text { ilure }\end{array}$ & Failure mode \\
\hline $\begin{array}{c}\text { HPFRCC- } \\
180-\mathrm{F} 2.0\end{array}$ & $\# 11$. & $82.16 \mathrm{~kJ}$ & Scabbing \\
\hline $\begin{array}{c}\text { UHPC- } \\
180-\mathrm{F} 0.0\end{array}$ & $\# 2$. & $6.13 \mathrm{~kJ}$ & Perforation \\
\hline $\begin{array}{c}\text { SFRC- } \\
60-\mathrm{F} 2.0\end{array}$ & $\# 6$. & $33.11 \mathrm{~kJ}$ & Scabbing \\
\hline $\begin{array}{c}\text { NC- } \\
60-\mathrm{F} 0.0\end{array}$ & $\# 2$. & $6.13 \mathrm{~kJ}$ & Perforation \\
\hline
\end{tabular}




\subsubsection{Damage Assessment Based on Support Rotation}

The value of support rotation was traditionally used as a parameter for evaluating damage in impact and blast tests. This parameter based on the maximum dynamic deflection of structural components, which was measured by using a laser displacement meter and potentiometer.

During the single impact loading test, deflection-time history (see Fig. 5) exhibited by each specimen was recorded and used to calculate support rotation values. And then, corresponding damage level was evaluated according to the design criteria provided by TM 5-1300, the most representative protective design manual.

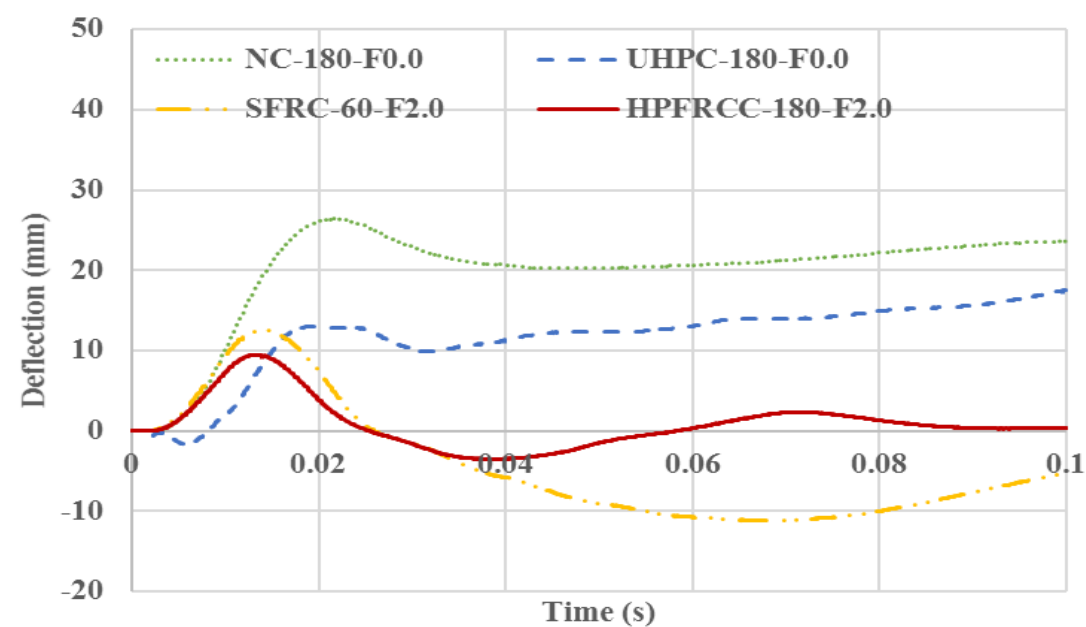

Fig. 5 Deflection-time history under single impact (Step \#2.)

Table 5 presents the damage level evaluated using conventional approach based on support rotation. The support rotation values of the slabs without steel fiber were found to be in the severe range of more than 12 degrees. The HPFRCC-180-F2.0 slab was in the light range of 1.8 degrees and the SFRC-60-F2.0 was in the Moderate range of 2.34 degrees. As a results, fiber reinforcement has a lot of benefits on Impact Resistance of FRC Slabs

Table 6. Damage assessment using conventional approach

\begin{tabular}{|c|c|c|c|}
\hline Specimens & $\begin{array}{c}\text { Maximum } \\
\text { deflection } \\
(\mathbf{m m})\end{array}$ & $\begin{array}{c}\text { Support } \\
\text { rotation } \\
\text { (degree) }\end{array}$ & $\begin{array}{c}\text { Damage } \\
\text { Level } \\
\text { (TM 5-1300) }\end{array}$ \\
\hline $\begin{array}{c}\text { HPFRCC } \\
180-F 2.0\end{array}$ & 25.10 & 1.80 & Light \\
\hline $\begin{array}{c}\text { HPFRCC } \\
180-F 0.0\end{array}$ & Punching & - & Severe \\
\hline $\begin{array}{c}\text { SFRC } \\
60-\mathrm{F} 2.0\end{array}$ & 32.76 & 2.34 & Moderate \\
\hline $\begin{array}{c}\mathrm{NC} \\
60-\mathrm{F} 0.0\end{array}$ & Punching & - & Severe \\
\hline
\end{tabular}




\section{Concluding remarks}

The purpose of this study is to evaluate the impact resistance of FRC slabs strengthened with various fiber. The difference between SFRC and UHPFRCC was also observed by experimental program. The conclusions drawn from this research are steel fiber reinforcement can increase the capacity of RC slabs under impact loading

Experimental assessment of RC slabs under low-velocity impact loading condition was conducted. Fiber reinforcement increased the ductility, shear force, and energy dissipation capacity of the members. The presence of steel fiber also resulted in superior damage tolerance with reduced fragmentation of concrete under low-velocity impact loading condition. In addition, steel fiber reinforcement showed significant enhancement especially in maximum deflection, residual deflection, and vibration reduction.

This work was supported by the National Research Foundation of Korea (NRF) grant funded by the Korea government (MEST) (NRF-2016R1A2B3011392).

\section{References}

1. H. Aoude, et al. "Response of steel fiber-reinforced concrete beams with and without stirrups, ACI Strct. J.”, 109, 3, pp.359 (2012)

2. N. Banthia, et al. "Impact behaviour of concrete beams, Mat. \& Strct.", 20, 4, pp.293302 (1987)

3. V. Bindiganavile, N. Banthia, "Polymer and steel fiber-reinforced cementitious composites under impact loading_Part 2: Flexural toughness" Mat. J., 98, 1, pp.17-24 (2001)

4. P.H. Bischoff, S.H. Perry, "Compressive behaviour of concrete at high strain rates, Mat. \& Strct.", 24, 6, pp.425-450 (1991)

5. L. Daudeville, Y. Malécot, "Concrete structures under impact, European J. of Env. \& Civil Eng.", 15, 1, pp.101-140 (2011)

6. K. Fujikake, et al. "Impact response of reinforced concrete beam and its analytical evaluation, J. of Strct. E.”, 135, 8, pp.938-950 (2009) 